\title{
Emergence Without Nitrous Oxide
}

\section{Instructions}

1. As soon as possible, given the surgical conditions, reverse neuromuscular blockade.

2. Get the patient breathing on their own by using synchronized intermittent mandatory ventilation (SIMV) or pressure support ventilation (PSVPro). Ventilation goals:

(a) Patient initiates all of their own breaths.

(b) Minimal pressure support of $5 \mathrm{cmH}_{2} \mathrm{O}$.

(c) Trigger flow of $2 \mathrm{~L} / \mathrm{min}$.

(d) $\mathrm{ETCO}_{2}$ of 50 .

(e) RR 8-10.

3. Turn down the sevoflurane. Goal is for the end-tidal sevoflurane to be 0 as soon as possible.

4. To ensure lack of awareness while patient is breathing off sevoflurane:

(a) Give propofol 20-30 mg q10 min (dose titrated to patient tolerance) OR

(b) Use propofol gtt $25-50 \mathrm{mcg} / \mathrm{kg} / \mathrm{min}$ but discontinue $10 \mathrm{~min}$ prior to extubation

5. To ensure analgesia:

(a) Give fentanyl $25 \mathrm{mcg}$ at a time, titrated to $\mathrm{ETCO}_{2} 50$ and RR 8-10.

(b) If a patient breathes at a faster rate to a lower $\mathrm{ETCO}_{2}$ than this while still under anesthesia, they will breathe even faster when awake. This indicates that the patient's pain is poorly controlled.

6. Signs that patient is in pain, the anesthetic is too light, and/or the patient will move/awaken too early
(a) Tachypnea
(b) Low $\mathrm{ETCO}_{2}$
(c) Sigh breaths
(d) Irregular respiratory pattern
(e) Tachycardia
(f) Hypertension
(g) Sweating 